Dossiê

\title{
A vida dos maracás: reflexões em torno de um instrumento ritual entre os Pumé da Venezuela
}

\author{
Gemma Orobitg Canal \\ Universidade de Barcelona, Catalunba, Espanha \\ orobitg@ub.edu
}

RESUMO: A partir da apresentação de alguns episódios da biografia de um maracá e dos laços que se estabelecem, no momento da passagem para a idade adulta, entre cada homem pumé e seu maracá, este texto apresenta diferentes ideias para se pensar as relaçôes entre os seres humanos e alguns objetos. Neste caso, podemos falar de uma identidade entre um ser humano e um maracá. Esta equivalência está apoiada na ideia de que o corpo é um recipiente oco que deve ser fabricado e sustentado para poder acolher as essências vitais que permitem viver, quer os homens, os animais, os deuses e espíritos, as plantas e mesmo os objetos.

PALAVRAS-CHAVE: Maracás, seres humanos, seres vivos, pessoa, artefatos, ritual.

\section{Introdução}

Como a maior parte das sociedades de caçadores-coletores, os Pumé possuem uma série de objetos muito limitada. Para além de cestos, arcos e flechas ou canoas, utilizados, respectivamente, para colheita, caça ou pesca, encontramos entre eles apenas alguns objetos 
cotidianos como pequenos teares para a fabricação de redes ou raladores e peneiras para a mandioca, além de alguns objetos rituais. Dentre estes últimos, o maracá é o mais valorizado. Cada homem pumé possui um maracá:

Meu maracá, eu não o empresto jamais. Ontem, eu o deixei com meu sobrinho Trifon para cantar o (ritual do) Tohé. Ele teve medo, é um maracá muito poderoso. Ele me disse: apanhei fortemente durante toda a noite com o seu maracá! (Riecito, Junho de 1992)

Assim falou um homem pumé, Cesar Díaz, aquele que os Pumé reconhecem como possuindo a maior maestria no canto do ritual do Tóhé, assim como um extraordinário conhecimento do mundo dos deuses. Cumpre dizer que ele foi o mestre da maioria dos homens adultos que cantam atualmente o Tôhé. Através das suas palavras, descobrimos a ideia de uma estreita relação entre um indivíduo e um objeto, mas igualmente a de uma intencionalidade própria ao objeto.

A partir das relaçóes estabelecidas entre cada homem e seu maracá, este texto mostra a homologia entre um corpo humano e um artefato, entre a construção de um corpo e a de um objeto. Mesmo que as operaçôes sejam bem diferentes, os cuidados dos corpos da mãe e da criança durante a gravidez e o nascimento e os processos técnicos seguidos para a fabricação do maracá compartilham de um mesmo objetivo: produzir um corpo (ikhará) pronto para acolher as essências vitais (pumethó) que animam todos os seres, mas que possuem, todavia, a necessidade destes corpos (ikhará) para se manifestarem. As relaçóes entre os homens pumé e seus maracás permitem igualmente explorar a identidade e a imbricação entre processos vitais e processos técnicos. Os corpos dos homens, assim como os maracás, devem ser constantemente sustentados. No momento da passagem à idade adulta - quando cada jovem pumé recebe um maracá - até a morte do indivíduo, os homens e os maracás estabelecem relaçôes de responsabilidade e dependência mútuas.

Como se tece a relação de cada homem com seu maracá? Como ela se desenvolve ao longo de toda a vida de um indivíduo pumé? Por que os maracás podem agir sobre aqueles que os detêm? Quando e por que o fazem? Estas são algumas das questóes que orientaram a escrita deste texto, tendo em conta esta dupla natureza do maracá: ao mesmo tempo prolongamento do indivíduo e agente animado instigador de situaçôes por vezes indesejadas por ele. Ainda que verídica, essa afirmação deverá ser nuançada ao levarmos também em 
consideração isto o que podemos chamar da "vida dos maracás", isto é, a biografia do nascimento à morte - de cada um destes objetos (Kopytoff, 1986: 66). Ao incorporar esta perspectiva, o que a princípio fora pensado como uma relação entre um indivíduo e um objeto torna-se, de fato, uma relação entre dois seres vivos.

Tal relação faz todo sentido se nos ativermos à ideia pumé - presente entre outras culturas ameríndias - de que não apenas os humanos e os animais, mas também os deuses e outros seres não humanos (incluindo os objetos) participam de uma noção geral da pessoa na qual aquilo o que, na tradição ocidental, chama-se o "corpo humano" é, de fato, um objeto material cuja vitalidade não está inscrita na matéria mesma, mas na essência que a anima e que não pode agir senão através da sua mediação. Eduardo Viveiros de Castro aborda a questão do corpo ameríndio nestes termos; não importa que corpo, inclusive o corpo humano, seja concebido como sendo o envelope exterior de uma alma. Em algumas línguas indígenas, sublinha Viveiros de Castro, a palavra "corpo" possui, além disso, o sentido de "envelope" ou "caixa" e serve igualmente para nomear coisas como cestos, chapéus e casas... Todas essas coisas são o "corpo-envelope" de qualquer outra (Viveiros de Castro, 2012: 133). Entre os Pumé, a "caixa”, a "carapaça” ou mesmo o "couro" são também algumas das imagens evocadas para se referir ao corpo (ikhará), representado como um continente físico oco, pronto para ser habitado por diferentes "essências vitais" (pumethó) que insuflam a vida nos seres.

Entretanto, essa relação não é sistemática. $\mathrm{Na}$ introdução do livro The Occult Life of Things: Native Theories of Materiality and Personhood (2009), Fernando Santos-Granero se refere, sem pretender ser exaustivo, às múltiplas maneiras de ser um objeto no mundo tal como vivido pelos indígenas. Nas ontologias ameríndias, os diferentes regimes de objetos (object regimes), para retomarmos a expressão de Stephen Hugh-Jones (2009), estariam ligados aos diferentes graus de competência comunicativa, subjetividade e "agentividade" atribuídos não somente aos objetos, mas a todos os seres, e que servem para classificá-los e hierarquizá-los enquanto seres sociais (Santos-Granero, 2009: 8-11).

Um exemplo neste sentido nos é fornecido por Felipe Ferreira Vander Velden em seu estudo sobre as flechas para a caça dos Karitiana (Tupi-Arikém, Rondônia). Para estes índios, as flechas possuiriam uma "agentividade" reprimida que deve ser ativada pelo consumo da carne e do sangue dos animais de caça. Do contrário, elas apodrecem, morrem ou, segundo o mito, se transformam em animal peçonhento. Mas isso não é tudo. Ainda 
segundo o mito, o contato das flechas com o sangue humano ativa excessivamente e perigosamente sua "agentividade". Neste caso, elas devem ser abandonadas na mata a fim de conjurar o infortúnio do caçador que as possui. A observação de uma "agentividade" particular destes objetos, seja reprimida, seja excessiva, é o que permite ao autor afirmar que, mesmo que reconheçamos nelas uma certa subjetividade, "as flechas karitiana, não são exatamente pessoas" (Van der Velden, 2011: 233-250).

Quanto aos maracás pumé, sua identidade com o ser humano é algo inerente à concepção indígena deste mesmo objeto. Não somente o maracá possui uma estrutura análoga àquela da pessoa humana (um corpo e uma essência vital), mas a vida de um maracá - sua fabricação, desenvolvimento, manutenção e morte - é mesmo pensada como algo similar ao desenvolvimento ontogênico humano. Para o ser humano, assim como para os maracás, os processos vitais requerem a realização de todo um conjunto de técnicas e práticas a fim de que os diferentes corpos (ikhará) adquiram as condiçóes necessárias para acolherem as "essências vitais" (pumethó) que os animam. O ikhará, este corpo/envelope, não é algo que é dado, mas que deve ser fabricado e continuamente mantido a fim de estabelecer e manter os laços entre as "essências vitais" (pumethó) que lhe dão vida e que não podem agir sem o seu intermédio. A apresentação simultânea da biografia de um homem no momento da passagem à idade adulta e aquela do maracá que ele recebe nesse momento esclarecerá as questóes relativas às relaçóes entre os processos técnicos e os processos vitais e à compreensão desta qualidade de ser vivo que pode ser atribuída a certos objetos.

Vários estudos sobre as Terras Baixas da América do Sul sublinharam que os índios desta regiáo reconhecem em alguns de seus objetos a capacidade de agir de maneira autônoma e, por isso, eles estabelecem analogias ontológicas entre esses objetos e os seres humanos. A fabricação dos "corpos” dos primeiros é análoga à fabricação dos segundos. Essa ideia de corpo permite estabelecer equivalência entre essas duas categorias de seres. Encontramos diversos exemplos etnográficos: os desenhos e imagens cashinahua permitem o desenvolvimento de corpos humanos assim como de certos objetos (Lagrou, 2009); entre as redes e o corpo dos bebês urarina se estabelece uma relação de companhia e conservação que permite à criança crescer protegida (Walker, 2009); entre os Kuna, o processo de fabricação do corpo humano representa o modelo de fabricação de certos objetos como as esculturas em madeira dos espíritos guardióes (Fortis, 2014); entre os Wayana, as habilidades técnicas para a confecção de diferentes objetos que reproduzem as atividades 
criadoras dos demiurgos são pensadas como fundamentais na medida em que ativam as mudanças na vida da pessoa, de modo que cada etapa da vida do indivíduo está em relação com os materiais, as técnicas e a realização dos objetos específicos que possuem componentes humanos, uma vez que os objetos são concebidos em sua origem enquanto corpos transformados (Van Velthem, 2009). Em geral, o resultado desta fabricação/desenvolvimento simultâneos é o estabelecimento entre o ser humano e o objeto de um laço de parceria e, em certos casos, de parentesco mesmo, laço que se mantém ao longo de toda a sua vida e mesmo após a morte.

\section{Dos objetos como seres...}

Os Pumé, conhecidos também na literatura etnográfica como Yaruro, são um grupo de pescadores e caçadores-coletores que praticavam até muito recentemente um nomadismo sazonal nas savanas dos Llanos du Apure (Venezuela), onde habitam. É preciso sublinhar o caráter disperso dos diferentes assentamentos pumé ao longo de uma vasta zona geográfica entre as bacias dos rios Arauca, Cunaviche, Riecito, Capanaparo e Cinaruco; o que favorece algumas particularidades culturais, especialmente quanto às estratégias de subsistência adotadas. Atualmente, o grupo é constituído por 9.476 indivíduos, segundo o último recenseamento indígena venezuelano (2011). A origem linguística do Yaruro ou Pumé é controversa, mas a maior parte dos estudos sustentam tratar-se de uma língua independente, com nove dialetos.

Hoje em dia, aos olhos de um observador exterior, a vida cotidiana dos Pumé é bastante difícil. $\mathrm{O}$ contato com os não-indígenas provocou a sua sedentarização compulsória, dificultou o acesso aos recursos para subsistência, diminuiu o território tradicional do grupo e provocou o aumento das taxas de mortalidade. $\mathrm{O}$ encontro com este mundo exterior data da instalação, no século XVIII, de missóes jesuítas, dominicanas e capuchinhas na região do Apure. Ao longo dos anos 1920, os contatos se multiplicaram a partir da implantação de colonos colombianos e venezuelanos na região.

Os Pumé possuem uma consciência aguda da precariedade da sua situação atual e das ameaças à sua sobrevivência. Todos os etnólogos que se aproximaram deles ao longo de todo o século XX concordam em um ponto: os Pumé se dissociaram deste mundo; eles 
dificilmente se veem sobrevivendo nesta terra. Dedicam grande parte do seu cotidiano ao sonho e ao ritual do Tóhé, cerimônia que aparece a primeira vez nas crônicas dos missionários do século XVIII numa descrição que em tudo se assemelha ao ritual tal como podemos observá-lo nos dias atuais. Ontem e hoje, através do canto do Tóhé se instaura um diálogo entre os homens e os deuses. É em torno deste diálogo que toda a vida dos Pumé se constrói e, por isso, ele é constantemente procurado.

Não é fácil fazer os homens pumé falarem de seus maracás. Ainda mais difícil é pedir que mostrem-nos fora do ritual do Tóhé. O maracá, que desempenha um papel essencial, é, com efeito, o único instrumento a acompanhar os cantos dos homens adultos durante a cerimônia. É ele quem lhe garante sua eficácia mesmo. Ao longo do ritual, os maracás são investidos com as "essências vitais" (pumethó) dos tío, seres intermediários entre os humanos e os deuses (oté). Segundo os Pumé, os maracás são os "corpos" (ikhará) dos tío. Assim é para tudo o que vive: os homens, os deuses e outros espíritos, os animais, as plantas e alguns objetos. Cada uma destas entidades é composta por um ikhará e por um ou mais pumethó. A palavra pumé ikhará, que designa o "corpo", significa mais precisamente "pele" (i) "couro" (-khará). A palavra pumethó, empregada para se referir à essência que dá vida aos seres, significa literalmente "índio" (pumé) e "raiz ou tronco" (-thó), em outras palavras, é aquilo o que permite aos índios existirem, enraizarem-se e estabelecerem-se na vida.

Não obstante, como pretendo demonstrar, estas duas palavras, ikhará (“corpo”) e pumethó ("essência vital") são igualmente utilizadas quando falamos dos deuses, dos espíritos, dos animais, das plantas e dos objetos. O pumethó é a essência que anima todos os seres e o ikhará é o envelope físico sem o qual o pumethó não poderia se manifestar e agir. Contudo, o ikhará é forjado e conservado para estabelecer laços estáveis com os pumethó mais adequados para aportar-lhe seu sopro. A noção pumé de "corpo" é aquela de um “corpo-objeto" ou, sobretudo, de um “artefato”. Deste modo, podemos afirmar que os seres vivos, humanos e não-humanos, não poderiam existir sem o intermédio dos artefatos que lhes proporcionam sua materialidade.

Os tío que habitam os maracás são os pumethó das crianças mortas no parto ou ainda bem pequenas, antes de aprenderem a falar, assim como aquelas que sofreram aborto. Eles nasceram humanos sem poderem, contudo, tornarem-se humanos e vivem junto aos deuses (oté), aos quais servem de intermediários. Justamente por não serem nem humanos - 
ainda que tenham nascido humanos - nem deuses - mesmo que, assim como eles, sejam seres de sangue frio que vivem em terras distantes. Os tío necessitam toda uma série de mediaçôes físicas (ikhará) para fazerem chegar aos humanos os conselhos e dádivas dos deuses (oté). Alguns pássaros ou outros animais como o jaguar (em latim, Panthera onça) podem abrigar temporariamente os pumethó dos tío a fim de lhes permitir manifestarem-se diante dos humanos. Do mesmo modo, os homens que cantam durante o ritual do Tóhé emprestam momentaneamente suas bocas e suas vozes à expressão destes seres intermediários. Contudo, ainda segundo os Pumé, os maracás, assim como as pedras chamadas tió tandé (pedras dos tío) ou tío hô (casa dos tío) são verdadeiros "corpos" (ikhará) dos tío.

Uma relação de identificação vem se estabelecer entre cada homem e seu maracá assim como entre os tío tandé (pedras dos tío), estes pequenos seixos que cada um conserva cuidadosamente num pequeno saco mantido sempre perto daquele que protege o maracá. Durante o Tóhé, cada cantor pronuncia as palavras dos deuses com a ajuda do seu maracá. O pequeno saco que contém estas pedrinhas, os tío tandé, é preso a um poste próximo ao cantor que ao longo de todo o ritual sopra sobre ele a fumaça do cigarro. No decorrer do ritual, através dos maracás, mas também dos tío tandé, os tío e, por meio deles, os deuses (oté) participam da vida pumé.

Os Pumé cantam o ritual do Tóhé do pôr do sol ao amanhecer, quatro ou cinco vezes por semana. No desenrolar do ritual, auxiliadas pelos maracás, as essências vitais (pumethó) dos homens adultos que cantam deixam seus corpos (ikhará) para percorrerem os longos caminhos que levam às terras de alhures. De sua parte, os tío, estes seres intermediários entre os homens e os deuses, vêm aqui, no interior dos maracás, para fazerem chegar aos Pumé as palavras dos deuses (oté). Mesmo sendo os homens adultos a conduzirem a cerimônia, os jovens, os velhos, as mulheres e as crianças também participam ativamente. "Nós cantamos para viver", explicou um homem pumé. Com efeito, trata-se de um ritual que detém ainda hoje um papel estruturante nos ciclos da vida e na organização da vida social pumé.

A passagem dos homens à idade adulta se faz através da iniciação ao canto por meio da cerimônia do Tôhé. A cura das doenças requer a intervenção, durante o Tóhé, daqueles que aprenderam, também no ritual, a curar o corpo (ikhará) e a essência vital (pumethó). Os acordos matrimoniais e os casos de poligamia são igualmente decididos durante a 
cerimônia do Tôhé. A resolução de conflitos cotidianos relativos às atividades de subsistência e, sobretudo, aqueles que decorrem do contato com os brancos são também organizados durante o canto do Tóhé. A comunicação com os mortos, assim como o futuro dos Pumé e da humanidade necessita igualmente a celebração do Tôhé, desta comunicação entre os homens e os deuses, e por isso os maracás são um elemento indispensável.

A palavra pumé para "maracá" é chî, que é usada também para designar o coração. Segundo os Pumé, o coração é uma das partes do corpo humano (ikhará) graças ao qual o indivíduo pode continuar a viver, mesmo se a sua essência vital (pumethó) estiver ausente. O coração é também o lócus do pensamento e do conhecimento. Aqueles que cantam o Tóhé explicam que é graças ao som dos seus maracás que cada um dos seus pumethó - que partem durante o ritual, sendo o seu objetivo mesmo a viagem às terras dos deuses - pode regressar do exterior, reencontrar e reintegrar o corpo, ou seja, continuar a viver.

Com efeito, a parte cantada do Tóhé é precedida por uma suíte de solos de maracá, regida pelo cantor que dirige a cerimônia e por aquele que o auxilia. É o momento, dizem eles, quando a música dos maracás acompanha a viagem dos "pumethó principais" de todos os homens adultos que participam do Tóhé através das terras dos deuses (oté dabú), bem como a chegada dos outros pumethó - chamados "pumethó cantores" - que vêm habitar temporariamente os "corpos" (ikhará) de todos aqueles que cantaram ao longo de toda a noite. Cada homem pumé possui ao menos duas essências vitais, o "pumethó principal” e o "pumethó cantor".

O primeiro é a essência vital com a qual o indivíduo nasce, aquela com a qual ele vive e sonha, pois é a essência principal que viaja pelas terras distantes dos deuses durante o sonho e o canto do Tóhé. A outra essência vital é aquela que permite a todos os homens pumé escutar os tío e, através deles, os deuses (oté), durante o ritual. Ela adentra o corpo do cantor no início do Tóhé e não o deixa até que a cerimônia chegue ao fim, para permitir que a essência principal reintegre o corpo e que a vida siga seu curso. Os maracás permitem esta operação de intercâmbio de essências vitais que garantem o bom andamento do ritual do Tóhé e, por conseguinte, a própria existência dos homens e da sociedade.

Enquanto canta, o homem aproxima o maracá o mais perto possível da sua cabeça para escutá-lo bem e receber, desse modo, a energia da palavra dos oté (deuses) que lhe chegam através dos tío que animam o maracá. Tratam-se de palavras relativas à existência, tal como ela se desenrola na terra dos deuses e nesta terra. Relativas aos doentes - às causas 
e tratamentos de suas doenças -, aos conflitos da vida cotidiana e suas resoluçóes, à organização da vida da comunidade, às transformaçóes culturais decorrentes das políticas do Estado venezuelano, etc... Ao amanhecer, os últimos refrōes do canto do Tóhé encorajam a partida das essências vitais (pumethó) dos cantores, de modo a permitir o retorno dos "pumethó principais" dos homens que participaram do ritual. É graças à música dos maracás, insistem os homens pumé, que cada essência vital (pumethó) consegue reencontrar seu lugar nos seus corpos (ikhará).

Os maracás intervêm em dois níveis, portanto. De um lado, no início do ritual, o tom de cada maracá permite aos diferentes "pumethó cantores" identificar seus ikhará, dentre aqueles homens que participam do Tóhé, de se incorporar neles e conduzir, assim, o ritual. É também graças ao som que eles produzem que os "pumethó principais" dos cantores podem retornar aos seus corpos, ao fim do Tóhé, e, desse modo, continuar a viver. Por outro lado, o maracá é habitado por diferentes essências vitais, aquelas dos tío, que os fazem viver, mas que podem também deixá-lo e matá-lo a ele e ao cantor. De fato, certos comportamentos do cantor ou daqueles que participam do ritual podem perturbar os tio que, subitamente, podem deixar o maracá e produzir importantes desgastes, tal como a morte imediata do cantor. Sem o auxílio do seu maracá, o homem não chega sequer a cantar e sua essência vital principal tampouco pode refazer o caminho de volta das terras dos deuses (oté), o que o permite reintegrar seu corpo (ikhará), recordar a viagem à terra dos deuses e continuar a existir.

\section{A fabricação dos corpos e dos objetos}

A eficácia dos maracás requer toda uma série de açóes que cada homem deve realizar junto ao seu, desde a sua fabricaçáo, entalhamento, conservação e emprego ritual até o seu fim, com a morte do cantor. Para ilustrar esta afirmação, descreverei sucintamente a experiência dos homens pumé no momento da passagem à vida adulta e a fabricação dos maracás enquanto atividades simultâneas que permitem aproximar a questão da imbricação entre processos técnicos e processos vitais e de abordar, deste modo, a lógica indígena da pessoa e das relaçôes sociais. 
Se todo homem adulto pumé possui um maracá é porque a passagem à idade adulta requer a iniciação ao canto do Tóhé e a viagem da essência vital por terras distantes. Esta iniciação ao conhecimento das terras dos deuses é feita a partir de um estado de enfermidade que, segundo as histórias de vida dos adultos pumé, persiste durante todo o período que precede a primeira experiência enquanto cantor solista na cerimônia do Tóhé, seja para dirigi-la, seja para participar da roda de cantos entoados pelos homens durante o ritual. Atinge-se este estado de enfermidade ao contrariar o comportamento esperado de um homem adulto. Em seus relatos, este período da juventude é descrito como aquele em que um excesso de relaçóes sexuais, ou ainda de relaçóes sem o consentimento dos adultos - um protocolo indispensável para o matrimônio - estimulam os deuses pumé a lhes punir, em particular através de um trickster cujo nome é Ici Ai. Assim os jovens caem enfermos. Suas essências vitais (pumethó) são conduzidas por Ici Aí pelas terras dos deuses, onde devem aprender a se comportar como homens adultos e, sobretudo, a cantar o Tóhé. Trata-se de um período que deve sempre ser estendido a fim de assegurar uma boa iniciação. Aqui e alhures, na vigília e nos seus sonhos, os jovens têm os seus comportamentos censurados pelos adultos e pelos deuses, para garantir o conhecimento das terras distantes na sua passagem à vida adulta.

Concomitantemente, um homem - o pai ou o tio do jovem e por vezes um adulto da própria comunidade reconhecido por suas habilidades como cantor - começa a fabricação de um maracá que será oferecido ao jovem que se encontra num estado de enfermidade e aprendizado do mundo de lá. A produção do maracá é um processo similar àquele da constituição de um corpo humano. Mesmo que as operaçóes realizadas sejam diferentes, é preciso sublinhar que elas respondem a um mesmo objetivo: o de produzir um corpo (ikhará) bom, pronto para acolher a essência vital (pumethó). Este é também o objetivo dos cuidados dispensados ao bebê pelos parentes desde a gravidez e o nascimento até o momento em que a criança pronuncia suas primeiras palavras.

Trata-se, sobretudo, de prescriçôes e interdiçôes alimentares, pela mãe e pela criança, fundadas na lógica da "participação" de qualidades. Assim, por exemplo, quando uma mulher está em fase de aleitamento, ela não pode comer da carne da cabeça-seca (em latim, Mycteria americana), pois se trata de uma ave que só começa a se mover tardiamente e a criança seria exposta ao mesmo perigo. Outra lógica que ajuda a explicar as prescriçóes e interdições alimentares relativas ao recém-nascido é aquela das categorias do quente e do 
frio. Ao nascer, o corpo da criança necessita uma alimentação específica para que seu sangue não seja nem tấo quente nem tâo frio, e possa, assim, acolher de modo conveniente a presença do pumethó (essência vital).

Por exemplo, enquanto a mãe amamenta a criança, ela não pode consumir o sangue do veado, ao passo que aquele do cão-da-pradaria lhe é prescrito. Os adultos pumé e as crianças menores, ao contrário, consomem o sangue do veado como uma vitamina ao passo em que aquele do cáo-da-pradaria, que é muito frio, lhes é interdito, sob o risco de morrerem (Orotbig, 1998: 150-52, 182). Durante todo o período da gestação e após o parto, a criança não é senão um corpo (ikhará) por se produzir, forjar e cuidar, de modo a criar o conjunto de condiçóes que permitirão que a sua essência vital principal ("pumethó principal") - aquele com o qual ela viverá e que viajará durante o seu sono e o Tôhé - se lhe incorpore para a vida, o que acontece quando a criança possui um ano e meio e já começa a se exprimir.

Quanto ao maracá, o homem encarregado da fabricação do objeto ritual irá primeiro procurar o fruto da cuieira ou cabaceira, como é conhecida em português (em latim, Crescentia cujete L.), que possui a forma oval característica dos maracás. $\mathrm{O}$ fruto que ele colhe para a fabricação do maracá possui um diâmetro de cerca de oito centímetros. A primeira operação que ele realiza sobre o fruto consiste em extrair a polpa do seu interior a partir de dois orifícios de aproximadamente cinco centímetros perfurados dois lados opostos da cabaça. É uma operação longa e minuciosa, pois o objetivo final é manter somente a carapaça verde e lisa do fruto, isto é, fabricar um artefato oco pronto para se tornar um bom corpo (ikhará).

A esta altura do processo, quando a superfície da carapaça ainda está verde e macia e antes que ela se seque, começa-se a entalhar diferentes motivos. Eles representam cenas da cerimônia do Tóhé, silhuetas humanas umas ao lado das outras apoiando-se pelos ombros ou troncos, do modo como as mulheres dançam durante o ritual, bem como a silhueta de um cantor solista com o seu maracá. A representação dos deuses é igualmente entalhada sobre a superfície do maracá: Kumañi, a criadora, sempre de braços abertos para acolher os Pumé, assim como a anaconda, Poana, com sua pele escamosa. Alguns animais, sobretudo pássaros e jaguares são também gravados na superfície da cabaça. Todas essas gravuras na superfície dos maracás mostram as conexôes e a simultaneidade entre o mundo dos homens e aquele dos espíritos. As imagens representam o ritual realizado pelos homens, aquele que 
permite o acesso às terras dos deuses, no mesmo plano que as imagens dos espíritos criadores, além de certos animais, especialmente aqueles que permitem a expressão dos tío.
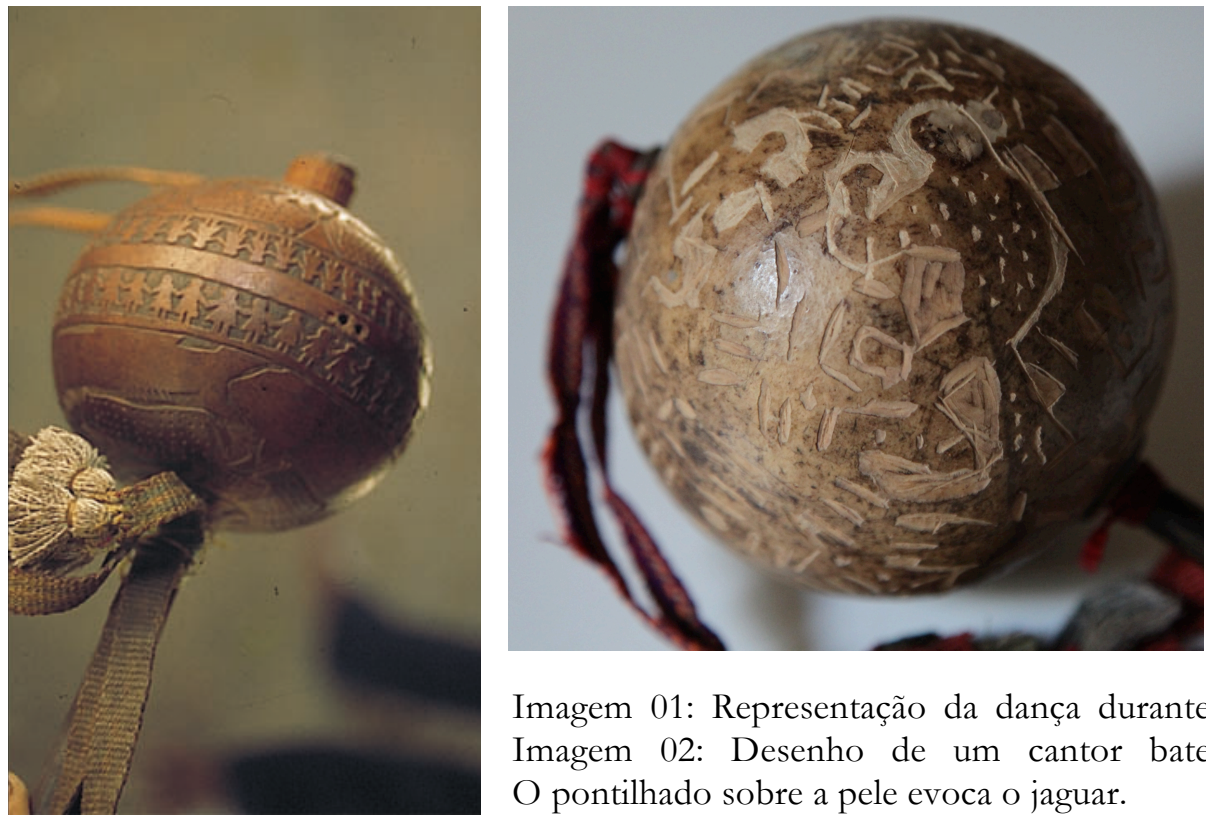

Imagem 01: Representação da dança durante o ritual do Tôhé. Imagem 02: Desenho de um cantor batendo seu maracá. O pontilhado sobre a pele evoca o jaguar.

Ainda que os motivos sejam semelhantes, não há maracá que seja a réplica de outro. Explicam que a decoração dos maracás é uma figuração inspirada nas viagens daquele que o fabrica através das terras dos deuses, durante os sonhos ou os cantos do Tóhé. A criatividade das gravuras, a originalidade das composiçôes entalhadas nos maracás, assim com a individuação da experiência da enfermidade que marca a passagem à vida adulta de um homem pumé são processos análogos e simultâneos que servem para singularizar o indivíduo e o maracá. Contudo, ao mesmo tempo em que esta identificação entre o homem e o objeto singulariza um e outro, ela também os engaja num complexo de relaçôes sociais no qual estáo implicadas as relaçóes entre os gêneros, entre os homens adultos, entre os humanos e, por fim, entre os humanos e os deuses. A última etapa da fabricação do maracá consiste em atravessar a cabaça com um cabo de madeira em sua parte superior e, por vezes também na parte inferior, decorada com cordóes coloridos tecidos como pingentes. 

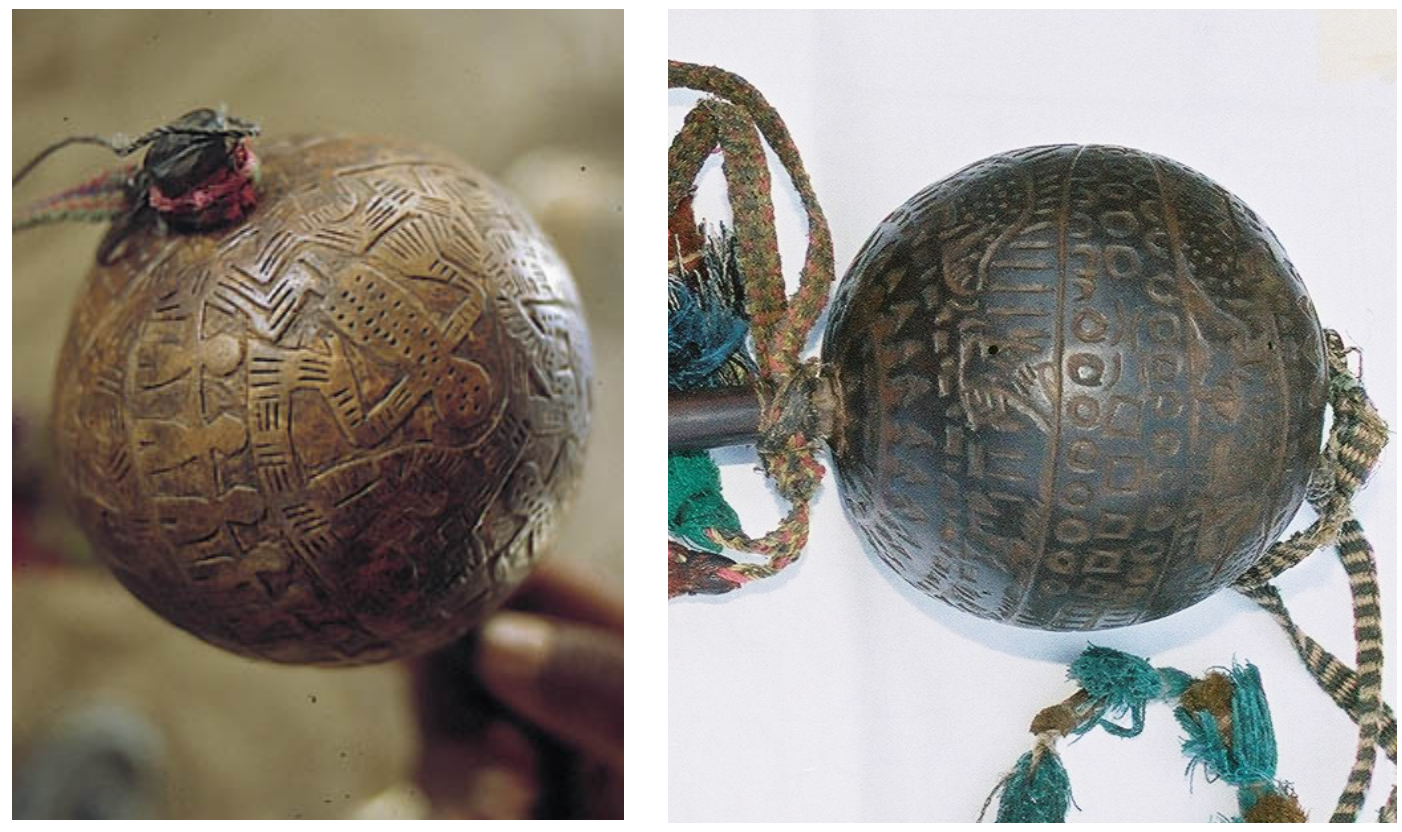

Imagem 03: Representação de Kumañi, a criadora, com os braços estendidos para acolher os Pumé. Imagem 04: Desenho de Poana, a anaconda, com sua pele escamosa.

Uma vez entalhada a superfície, a cabaça torna-se o corpo dos tío, o maracá (chî). O que foi trabalhado para que a cabaça se tornasse um maracá foi, sobretudo, o envelope, a pele, num processo análogo àquele que experimentam os corpos das mulheres quando da passagem à idade adulta. Se a entrada na vida adulta é marcada entre os rapazes por um tratamento do pumethó (essência vital), aquela das moças é marcada por um tratamento do corpo (ikhará). Durante as primeiras menstruaçóes, a moça é colocada em reclusão. Neste período, sua mãe e sua tia ou alguma outra mulher da família cuidarão do seu corpo. Elas lhe dão banho, lhe massageiam o corpo e o rosto para modelar suas formas. É também a partir deste momento que as mulheres podem pintar suas faces, especialmente durante a cerimônia do Tóhé (Petrullo, 1939: 253). Um hábito, dizem os Pumé hoje em dia, o qual elas praticam com grande prazer. Os desenhos sobre os rostos das mulheres não são jamais figurativos como aqueles dos maracás, mas são compostos pelas mesmas formas geométricas e monocromáticas que encontramos na superfície do instrumento ritual (Petrullo: 1939, Platô 22). Tal relação entre os maracás e os corpos das mulheres no momento da passagem à vida adulta poderia explicar o fato de somente elas poderem transportar o maracá do marido durante os deslocamentos da família - sempre dentro de pequenos sacos, pois os maracás não devem ser expostos à luz do dia. 
As mulheres se ocupam também de guardar e transportar os seixos, as "pedras dos tío" (tio tandé), onde os tío também habitam durante o Tóhé. Neste caso, são as mulheres que o transmitem a seus filhos quando estes atingem a idade em que podem cantar o ritual. As pedras dos tío são herdadas e transmitidas pelas mulheres (Orotbig, 1998: 140). Quanto ao maracá, ele é identificado unicamente ao homem que o recebe no momento da passagem à idade adulta. É ele quem o conserva e que será sempre por ele auxiliado durante a cerimônia do Tóhé.

De fato, o jovem rapaz receberá o maracá indicando assim o fim do seu longo estado de enfermidade. É também o momento quando uma nova essência vital, aquela que será incorporada nele durante o ritual do Tóhé, o "pumethó cantor", se liga a ele por toda a vida. Outro episódio recorrente nas histórias de vida dos homens adultos nesse período se refere ao momento em que as pedrinhas nas quais os tío habitarão, aquelas que se chocam umas com as outras produzindo o som do maracá, aparecem no seu interior sem que ninguém as introduza. $\mathrm{O}$ jovem recebe através dos sonhos a confirmação deste fato da parte dos próprios tío que adentraram seu maracá e que lhe acompanharão por toda sua vida ao longo das cerimônias do Tóhé. Uma relação exclusiva e estreita começa a se estabelecer entre o indivíduo e seu maracá, uma vez que aquele se torna o "corpo" (ikhará) de algum tío:

As pedrinhas do maracá - explicou César Diaz - não são daqui. Elas aparecem sozinhas dentro dele. Eu não posso mostrá-las pra você porque o espírito que cuida delas se enfureceria. Eu não as mostro nem mesmo aos meus filhos. Não as retiro senão quando estou sozinho, sem minha esposa. Elas são pequenas e redondas, essas pedrinhas. Não são brancas como aquelas do rio. Elas aparecem de repente, todas coloridas, dentro do maracá... (Riecito, Junho de 1992).

Cada homem adulto que participa no ritual do Tôhé possui o seu próprio maracá. Raramente aceitam emprestá-lo ou mesmo mostrá-lo. Uma relação íntima se estabelece entre os indivíduos e seus maracás até o ponto em que o destino do indivíduo está ligado ao do objeto. Veja-se aqui o relato de um homem pumé que narra diferentes episódios que ligam a vida dos homens àquela dos maracás. César Diaz conta sobre dois homens que partiram em viagem e suas duas mulheres que aproveitaram para vender seus maracás a dois estrangeiros. Ele relembra também o dia em que, furioso pela morte de seu filho, 
ele quebrou seu próprio maracá. Finalmente, Diaz recorda-se ainda o destino fatal de um pumé que vendeu seu maracá a um antropólogo:

Eulogio possuía um belo maracá e Patrício também. Dois brancos levaramnos consigo. Eulogio e Patricio haviam se ausentado da aldeia. Suas esposas, que guardavam os maracás, venderam-nos àqueles homens. Eles queriam utilizá-los em suas próprias danças. Eles jogaram fora as pedras do maracá e substituíram-nas por outras. Pouco tempo depois, um deles morreu na savana e o outro embarcou num pequeno avião que se espatifou. É algo muito perigoso. Eles morreram. Não podemos jogá-las fora, é preciso cuidar delas.

Eu passei pela mesma coisa. Eu tinha um maracá muito bonito. $\mathrm{Na}$ época, eu tinha apenas uma mulher. Cantei porque meu filho estava doente e não melhorava. Ele morreu. Eu fiquei furioso e quebrei o maracá. A mulher da criança morreu alguns dias depois (...).

O pai de Perdomo (um jovem da comunidade de Riecito) também morreu assim. Um antropólogo me disse: "Preciso de um maracá". "Eu tenho um, mas não vendo não", respondi.

Mas o pai de Perdomo rapidamente cedeu o seu. Ele vendeu com suas pedrinhas por 300 bolívares. Ficou muito contente. Não viveu mais do que um ano. Morreu logo depois disso. Os pumethó do maracá eles mesmos, os tío, lhe disseram durante o ritual. Ele não morreu magro, estava bem gordo até. Mas é assim que o espírito do maracá mata. Ele morreu e caiu (...) (Riecito, Junho de 1992).

Com efeito, os maracás dos Pumé, como as flechas de caça dos Karitiana são "criaturas perigosas" porque são delicadas e devem ser tratadas com cuidado. Nos dois casos, estes objetos necessitam ser constantemente conservados e é preciso estar sempre vigilante quanto aos cuidados que lhes são dispensados. Por isso, quando um objeto como esse é fabricado para um não-indígena ou uma criança, que não sabem cuidar dele, é preciso modificar seu processo de fabricação, de modo que ele não possua mais o objetivo de subjetivá-los, como é o caso dos maracás pumé, mas sim, ao inverso, de "de-subjetivá-los" para evitar consequências fatais (Vander Velden, 2011: 234).

Depois da iniciação que marca a passagem à idade adulta, uma relação de responsabilidade mútua se estabelece entre o indivíduo e os tío que animam seu maracá. Ao longo de toda vida, os homens têm a responsabilidade de manter os seus corpos e aqueles dos tío, os maracás, para criar as condiçóes que permitem a realização do ritual do Tôhé, contexto em que as relações entre os humanos, os tío e os oté (deuses) se desenrolam amplamente e no qual as questóes da existência encontram suas soluçóes. 


\section{A manutenção dos corpos e dos objetos}

Do momento em que a identificação do indivíduo e do objeto é estabelecida, a manutenção do corpo humano e aquela dos maracás tornam-se atividades simultâneas. Ao longo do dia, e normalmente fora da cerimônia do Tôhé, os maracás são cuidadosamente guardados num pequeno saco, no canto mais tranquilo e escuro da casa. Os tío, como os oté, não gostam de luz. Eles podem abandonar os maracás definitivamente se eles não forem mantidos fora do alcance do sol ou de outras coisas que os perturbem. É preciso, por exemplo, afastar os maracás das mulheres menstruadas e daquelas prestes a parir. Nestas circunstâncias, assim como quando há um óbito em alguma casa, os maracás são transportados para a casa de outros parentes, onde serão mantidos durante o período do resguardo ou do luto.

Do mesmo modo, a participação no Tóhé requer um jejum de alimentos sólidos e uma abstinência sexual nas horas que antecedem o ritual. Evita-se comer, explicam os adultos, "porque náo podemos evacuar nem vomitar durante a cerimônia". Os tío não gostam dos odores ruins. As relaçóes sexuais e o parto provocam um desequilíbrio do corpo, em particular um excesso de calor que os tío, sendo criaturas frias, devem evitar. É somente através destes cuidados concomitantes entre os corpos humanos e os corpos dos tío que o Tóhé pode se realizar. Quando a noite cai e tudo escurece, os cantores retiram seus maracás dos pequenos sacos que os protegem da claridade e chacoalham-nos para fazerem chegar as palavras ditadas pelos tío, aproximando-se deles para escutá-las. Durante toda a noite, cuidam dos seus maracás, enquanto exalam a fumaça dos seus cigarros, karamba, preparados pelas mulheres antes do ritual. Assim explica César Diaz: "Sopramos a fumaça sobre o maracá para cuidar dele, para que suas pedrinhas se sintam bem...” (Riecito, Junho de 1992).

Quando o homem morre, o destino do seu corpo e aquele do seu maracá é o mesmo. Cada homem é enterrado com o seu maracá. O pumethó que anima o corpo humano vai embora, como acontece durante o sonho e o canto do Tóhé, mas desta vez ele já não mais retornará. Doravante oco, o corpo é enterrado. Neste momento, os tío que animam o maracá, que o acompanharam durante o canto ao longo de toda a vida adulta do cantor, partem também para não mais voltar. $\mathrm{O}$ maracá torna-se oco, de nada serve mais. Ele é "jogado" - expressão genérica relativa ao destino dos corpos (ikhará) -, enterram-no com o corpo do homem ao qual ele esteve ligado numa relaçáo de responsabilidade mútua. 
Assim explicam os Pumé. As pedrinhas que aparecem repentinamente para animar o maracá também partem quando o cantor ou às vezes alguém da sua família morre. Mas é somente quando morre o cantor que as pedrinhas deixam para sempre o maracá, assim como a essência vital (pumethó) do cantor abandona definitivamente seu corpo (ikhará):

As pedrinhas, não é preciso procurá-las, elas devem aparecer sozinhas. As minhas apareceram dentro do meu maracá. Quando meu filho morreu, elas deixaram vazio o maracá. Eu quis chorar. Depois de algum tempo, elas reapareceram dentro dele. Elas haviam se ocupado do garoto e o acompanharam até o mundo de lá. Quando eu morrer, eu as levarei comigo. Não posso deixa-las para trás (...). As pedras partirão comigo (...) (César Diaz, Riecito, 1990).

\section{Conclusão}

Entre os Pumé, os homens e os maracás possuem uma relação vital. O corpo humano e os maracás são continentes que eventualmente podem acolher as essências vitais (pumethó) que insuflam vida nos seres. Com efeito, levando em conta a noção indígena de pessoa, estendida a todos os seres vivos, todos compostos de um corpo/envelope (ikhará) e de uma essência vital (pumethó), descobrimos uma homologia entre os seres humanos e alguns artefatos, como é o caso dos maracás. Estes objetos rituais e os homens possuem biografias do nascimento à morte - que se cruzam para se construírem numa relação de simultaneidade.

$\mathrm{Na}$ base deste processo vital, está a ideia de que o corpo (ikhará), esta entidade necessária para a manifestação das essências vitais (pumethó), é qualquer coisa que deve ser criado e cotidianamente mantido a fim que de acolher as essências que dão vida aos seres. As práticas que envolvem o nascimento de um ser humano e aquelas realizadas ao curso da fabricação de um maracá, mesmo que bem diferentes, possuem um mesmo objetivo: a constituição de um corpo (ikhará) capaz de receber as essências vitais (pumethó) que lhe permitem viver.

Trata-se de um processo que se inicia no momento do nascimento de alguém - seja um homem, seja um objeto, como os maracás - e que se desenrola ao longo de toda sua existência até a morte. 
No que diz respeito aos maracás, sua fabricação está ligada à passagem de um jovem rapaz à vida adulta através da iniciação ao canto do ritual do Tóhé. A partir deste momento, relaçóes de identidade se estabelecem entre um homem e o seu maracá, que ele recebe ao fim de um longo período de enfermidade após o qual ele adquire uma nova essência vital, aquela que permitirá, ao longo de toda sua vida, realizar o canto ritual. Percebemos, a partir deste momento em que a biografia de um homem e a de um objeto se ligam definitivamente, uma conexão estreita entre as práticas e as técnicas do corpo e os processos vitais.

Os homens, depois da passagem à idade adulta, e os maracás estabelecem uma relação de responsabilidade mútua que persistirá até a morte do cantor, que é também o fim do maracá. A fim de manter essa relação, os homens devem cuidar de seus corpos e dos seus maracás durante o Tôhé e fora dele. Estes cuidados compreendem uma série de relaçóes sociais. Assim eles tornam possível a ação dos tío que habitam o maracá, aqueles que garantem que as palavras dos deuses chegarão aos homens, enfim, aqueles que garantem as viagens de ida e volta das essências vitais, o "pumethó principal" e o "pumethó cantor", que se permutam a fim de permitir a boa realização do Tóhé. A existência dos indivíduos e da sociedade indígena é assim possível.

\section{Agradecimentos}

Este texto é dedicado à memória de César Diaz. Gostaria de agradecer meus colegas venezuelanos, Arelis Sumabila e Pedro Rivas, com quem compartilhei momentos intensos de pesquisa e amizade. Eles me encorajaram bastante a escrever este texto. Gostaria também de agradecer particularmente a Pedro Pitarch pela leitura atenciosa e comentários ao longo da escrita deste trabalho. Finalmente, gostaria de prestar meu reconhecimento aos pareceristas deste artigo pelos comentários sugestivos que me encorajaram a esclarecer e reforçar algumas das ideias principais deste trabalho. 


\section{Referências bibliográficas}

FORTIS, Paolo

2014 "Artefacts and Bodies among Kuna People from Panama". In Hallman, Elizabeth \& INGOLD, Tim (orgs.), Making and Growing: Anthropological Studies of Organisms and Artefacts. UK, Ashgate, pp. 89-106.

\section{Hugh-Jones, Stephen}

2009 "The Fabricated Body: Objects and Ancestors in Northwest Amazonia". In Santos-Granero, Fernando (org.), The Occult Life of Things: Native Amazonian Theories of Materiality and Personhood. Tucson, The University of Arizona Press, pp. 33-59.

KOPYTOFF, Igor

1986 "The Cultural Biography of Things: Commoditization as Process". In Appadurai, Arjun (org.), The Social Life of Things: Commodities in Cultural Perspective. Cambridge, Cambridge University Press, pp. 64-91.

\section{LAGROU, Els}

2009 "The Crystallized Memory of Artifacts: A Reflection on Agency and Alterity in Cashinahua Image-Making”. In SANTOS-Granero, Fernando (org.), The Occult Life of Things: Native Amazonian Theories of Materiality and Personhood. Tucson, The University of Arizona Press, pp. 192-213.

Orobitg, Gemma

1998 Les Pumé et leurs rêves: Étude d'un groupe indien des Plaines du Venezuela. Amsterdam, Éditions des Archives Contemparaines (Ordres Sociaux). 
GEMMA OROBITG CANAL. A VIDA DOS MARACÁS: REFLEXÕES EM TORNO...

Pertullo, Vincenzo

1939 "The Yaruros of the Capanaparo River, Venezuela". Anthropological Papers,

n. 11. Washington D.C., Smithsonian Institution. Bureau of American Ethnology. Bulletin 123.

SANTOS-GranERO, Fernando (org.)

2009 The Occult Life of Things: Native Amazonian Theories of Materiality and Personhood. Tucson, The University of Arizona Press.

VANDER VELDEN, Felipe

2011 "As flechas perigosas: notas sobre uma perspectiva indígena da circulação mercantil de artefatos". Revista de Antropologia, Sao Paulo, 5(1): 231-267.

VelTHEM, Lúcia Hussak van

2009 "Mulheres de cera, argila e arumã: princípios criativos e fabricação material entre os Wayana”. Mana 15(1): 213-236.

Viveiros de CASTRo, Eduardo

2012 "Cosmological Perspectivism in Amazonia and Elsewhwere". Master Class Series 1. Manchester. HAU Network of Ethnographic Theory.

WALKER, Harry

2009 "Baby Hammocks and Stone Bowls: Urarina Technologies of Companionship and Subjection”. In SANTOS-Granero, Fernando (ed.) The Occult Life of Things: Native Amazonian Theories of Materiality and Personhood. Tucson, The University of Arizona Press: 81-103. 


\title{
Créditos das fotos
}

\author{
Imagem 1. Orlando Barrial \\ Imagem 2. Gemma Orobitg \\ Imagem 3. Orlando Barrial \\ Imagem 4. Pedro Rivas \\ Imagem 5. Catherine De Clippel
}

\section{The Life of Maracás: Reflections upon a Ritual Instrument among the Pumé, from Venezuela}

\begin{abstract}
Between each Pumé man and his maracá there is an intimate relationship established at the time of passage to adulthood, to the point that maracas and men share a basic common biography and identity. This equivalence is based on the Pumé notion that the body is an empty vessel that must be manufactured and care to accommodate the vital essences which are a necessary condition to all beings, whether human, animals, gods and spirits, plants and even objects.
\end{abstract}

KEYWORDS: Maracás, Human Beings, Living Beings, Personhood, Artefacts, Ritual. 